\title{
Repeated large-volume epidural blood patches for the treatment of spontaneous intracranial hypotension
}

\section{Les colmatages sanguins («blood patch») périduraux à grand volume et à répétition pour le traitement de l'hypotension intracrânienne spontanée}

\author{
Bobby Mehta, MD $\cdot$ Jordan Tarshis, MD
}

Received: 22 January 2009/Accepted: 15 May 2009/Published online: 3 June 2009

(C) Canadian Anesthesiologists' Society 2009

\begin{abstract}
Purpose Refractory headache from spontaneous intracranial hypotension can be debilitating for patients. This report describes the use of repeated high-volume epidural blood patches to treat this condition.

Clinical features A 39-yr-old male presented with a history and diagnostic imaging findings consistent with spontaneous intracranial hypotension. The associated intractable and incapacitating headache was unrelieved by meperidine and a $20 \mathrm{~mL}$ lumbar autologous blood patch. Two weeks later, a second epidural blood patch of $45 \mathrm{~mL}$ autologous blood administered in the lower thoracic epidural space achieved partial relief. With symptoms persisting despite oral analgesics, a third blood patch was undertaken one month after the initial procedure. On this occasion, administration of $32 \mathrm{~mL}$ autologous blood into the mid-thoracic epidural space resulted in complete and lasting resolution of the headache.

Conclusion The ideal volume of blood injectate to achieve maximal effectiveness for an epidural blood patch is unknown. While many clinicians use a predetermined maximal volume, a volume titrated to patient symptoms is a suggested alternate approach.
\end{abstract}

\section{Résumé}

Objectif Les céphalées réfractaires causées par l'hypotension intracrânienne spontanée peuvent être débilitantes pour les patients. Ce compte-rendu décrit l'utilisation de

B. Mehta, MD · J. Tarshis, MD ( $\square)$

Department of Anesthesia, Sunnybrook Health Sciences

Centre, University of Toronto, 2075 Bayview Avenue,

Toronto, ON M4N 3M5, Canada

e-mail: jordan.tarshis@sunnybrook.ca colmatages sanguins périduraux répétés à grand volume pour traiter cette condition.

Éléments cliniques Un homme de 39 ans s'est présenté avec des antécédents et des résultats d'imagerie diagnostique indiquant qu'il souffrait d'hypotension intracrânienne spontanée. Les céphalées réfractaires et handicapantes associées à cette condition ont été soulagées grâce à de la mépéridine et un colmatage lombaire de sang autologue de $20 \mathrm{~mL}$. Deux semaines plus tard, un deuxième colmatage sanguin péridural de $45 \mathrm{~mL}$ de sang autologue administré dans l'espace péridural thoracique bas a permis un soulagement partiel. En raison de la persistance des symptômes en dépit de la prise d'analgésiques oraux, un troisième colmatage sanguin a été réalisé un mois après la première intervention. Lors de ce colmatage, une résolution complète et durable des céphalées a été obtenue grâce à l'administration de $32 \mathrm{~mL}$ de sang autologue dans l'espace péridural thoracique moyen.

Conclusion Nous ne connaissons pas le volume idéal de sang à injecter afin d'obtenir la plus grande efficacité lors d'un colmatage sanguin péridural. Alors que nombre de cliniciens utilisent un volume maximal prédéterminé, un volume titré selon les symptômes du patient pourrait constituer une approche alternative.

Intracranial hypotension is a condition characterized by a cerebrospinal fluid (CSF) leak secondary to a dural puncture or tear in the context of a diagnostic or therapeutic neuraxial procedure or, less commonly, trauma. On the odd occasion, spontaneous intracranial hypotension (SIH) can develop in the absence of an iatrogenic dural puncture, and a CSF leak may or may not be identifiable on imaging. Clinically, SIH (also called Schaltenbrand syndrome, after the German 
neurologist who first described it in 1938) ${ }^{1}$ mimics the presentation of the classic post-dural puncture headache (PDPH) syndrome, the hallmark of which is an orthostatic headache. Other symptoms may include neck pain, nausea, vomiting, diplopia, photophobia, tinnitus, and vertigo.

Treatment options for SIH are similar to those for PDPH. Conservative management includes bed rest, oral hydration, caffeine intake, abdominal binders, oral analgesics, and steroids. If these treatments are ineffective, an epidural blood patch (EBP) should be considered. Although EBP is considered the mainstay of treatment for PDPH, evidence for its effectiveness in SIH is limited and comes primarily from case reports and series. ${ }^{2-10}$

The success rate for an EBP is variable and depends on the size of the dural hole, timing of the EBP, and possibly the volume of blood used. In the obstetric population, a success rate of $70 \%$ for a single EBP has been reported, but $15 \%$ of patients needed a second or a third EBP to treat a PDPH from an inadvertent dural puncture with an epidural needle. ${ }^{11}$ For $\mathrm{SIH}$, the size and location of the leak is often unknown, and the success rate has been reported at about $30 \%$ for each blood patch. ${ }^{12}$ Injectate volume is variable and, traditionally, a volume of $10-20 \mathrm{~mL}$ is used. ${ }^{12}$ We present a case report of a patient with SIH requiring three EBPs, with the latter two involving large volume autologous blood injection. The patient provided written consent for publication of personal information contained in this report.

\section{Case report}

The patient was a 39-yr-old male who presented to the emergency department with a 3-month history of an orthostatic headache. His medical history was significant for chronic hepatitis B related to a childhood blood transfusion. He had no known drug allergies, was a non-smoker, and had no history of general anesthetics or neuraxial procedures. His only medications included meperidine and meloxicam for his headache, as well as lamivudine and tenofovir for his chronic hepatitis B.

The patient described a 3-month history of an occipital headache that was worse when sitting, standing, or coughing but improved in the supine position. The headache was so severe that he was unable to work, was consuming 500-600 mg of meperidine daily, and was often bedridden. He also complained of nausea and vomiting. There was no history of tinnitus, visual changes, photophobia, neck stiffness, fevers, or preceding trauma. On physical examination, he was alert and oriented, hemodynamically stable, and demonstrated no abnormalities of his cranial nerves or peripheral nervous system.

The patient's blood work revealed a normal hemoglobin and coagulation profile. He was admitted under the neurosurgical service for four days and underwent further investigations. A head computed tomography (CT) scan demonstrated a left subdural hematoma. A subsequent brain magnetic resonance imaging (MRI) revealed bilateral subdural hematomas, as well as pachymeningeal enhancement, cerebellar tonsils at the foramen magnum, and effacement of the supracellar and prepontine cisterns-finding in keeping with diffuse intracranial hypotension. An MRI of the cervical spine showed no abnormalities.

The patient was diagnosed with spontaneous intracranial hypotension and discharged home on conservative management. However, approximately 1 month later, he returned to the emergency department with the same persistent orthostatic headache and was re-admitted under the neurosurgical service for further evaluation. A repeat head CT scan revealed no significant changes (Fig. 1a), and an MRI of the thoracic and lumbar spines failed to identify a CSF leak into the spine soft tissues.

An anesthesia consultation was made and the history and physical findings were the same as noted above 1 month prior. Since the patient had debilitating symptoms for 4 months, he was no longer interested in conservative management. After informed consent, including an estimated probability of benefit of approximately $50 \%$, a lumbar epidural blood patch was performed in the left lateral decubitus position at the level of L3-4. A 17G Tuohy needle was employed using loss of resistance to air in the midline approach. Using a sterile technique, $20 \mathrm{~mL}$ of autologous blood was injected directly into the epidural space without any back pain or radicular symptoms elicited. The patient was kept supine for $4 \mathrm{hr}$ and then allowed to ambulate. There was no improvement in his symptoms, and he was discharged home the following day and continued on conservative therapies.

Two weeks later, the patient returned to hospital once again with the same debilitating headache. The patient was still consuming $600 \mathrm{mg}$ of meperidine daily, and he agreed to a second epidural blood patch. Similar technique was performed at T9-10 in the right lateral decubitus position. A total of $45 \mathrm{~mL}$ of autologous blood was injected slowly until the patient began to complain of back discomfort. There were no radicular signs or symptoms post-procedure, and the patient was instructed to remain supine for $1 \mathrm{hr}$, after which he was able to sit up comfortably with complete resolution of his headache and was discharged home.

The following day, the patient was phoned at home to evaluate for any recurrent symptoms. He stated that he experienced $6 \mathrm{hr}$ of complete pain relief followed by return of the headache, although less severe. The patient was advised to continue conservative management at this point and to taper his meperidine as tolerated.

On a follow-up encounter 2 weeks later, the patient was still complaining of a milder, although still debilitating, 
Fig. 1 a The computed tomography scan of the patient's head at time of presentation with bilateral subdural hematomas noted by the arrows. b The same patient 4 months later with complete resolution of the hematomas


orthostatic headache and requested a third EBP. A third EBP was performed using similar technique at T7-8 in the left lateral decubitus position. A total of $32 \mathrm{~mL}$ of autologous blood was injected slowly before the patient started to complain of back pain and thoracic radicular pain. This radicular pain disappeared within $5 \mathrm{~min}$. The patient remained supine for $1 \mathrm{hr}$ and had no headache upon rising and was discharged home. He remained pain free at telephone follow-up 2 days and 2 weeks later.

A repeat brain MRI the following month demonstrated a persistent appearance of an intracranial low pressure/volume state despite lack of symptoms. There was some reduction in the size of the bilateral subdural hematomas. Two months later, a head CT scan was repeated and revealed almost complete resolution of the hematomas (Fig. 1b) with only mild persistence of left uncal herniation and cerebellar tonsillar herniation. On a follow-up appointment a few weeks later, approximately 8 months after symptom onset, the patient was happy to report he had no residual headache and had returned to work.

\section{Discussion}

The incidence of SIH is approximately 5 per 100,000 ; symptom onset is usually in the fourth or fifth decade of life and occurs in females twice as often as males. ${ }^{13}$ Although the precise etiology of SIH is unknown, the main proposed pathophysiological mechanism includes underlying structural weakness of the dura leading to the development of dural defects prone to rupture. ${ }^{12,14}$ Additionally, it is thought that SIH results from the rupture of congenital perineural cysts or diverticula of spinal nerve sleeves, which are typically found in the cervicothoracic and thoracolumbar junctions. ${ }^{13,15}$ The most common sites for CSF leaks are the lower cervical and upper thoracic spine. ${ }^{16}$
It is generally accepted that the clinical presentation of intracranial hypotension, primarily the orthostatic headache, results from traction of pain fibres localized to the cerebral vasculature and meninges due to descent of the brain in the cranial vault when the patient assumes an upright position. In addition, compensatory cerebral vasodilation results from loss of CSF volume and pressure, further contributing to the headache. ${ }^{17}$ Subdural fluid (hygromas and hematomas) have been reported and are a volume compensatory phenomenon secondary to diminished CSF. ${ }^{18}$ The development of chronic subdural hematomas, as seen in this patient, is likely due to tearing of bridging veins.

Although SIH can be diagnosed by invasive procedures, such as lumbar puncture and intracranial pressure monitoring, MRI has now become the main diagnostic tool, as it is less invasive and demonstrates characteristic findings of SIH in the cranium and, occasionally, in the spine. Computed tomography myelography or radionuclide cisternography can also be used to evaluate the exact location and extent of CSF leak but requires an intrathecal injection, thus creating another hole in the dura with the potential to exacerbate the intracranial hypotension.

Despite the fact that no CSF leak was identified on MRI of the spine in our case, the patient's clinical presentation and characteristic changes on the cranial MRI were consistent with a diagnosis of SIH. After the diagnosis of SIH was made and conservative treatments failed, a decision was made to proceed directly with EBP, as some evidence suggests benefit from early EBP in SIH. ${ }^{5,19}$

The proposed mechanisms for the effectiveness of EBPs in treating intracranial hypotension from CSF leaks are thought to be due to tamponade of the dural hole as well as increased epidural and, consequently, intrathecal pressures by the injected blood, resulting in immediate relief of symptoms. ${ }^{6,12,17,20}$ It is thought that the "plugged" hole undergoes fibroblastic remodelling within $48 \mathrm{hr}$, collagen deposition within 2 weeks and, ultimately, scar formation 
by 3 months. ${ }^{6}$ Thus, it can be postulated that multiple EBPs and/or large volumes of blood may be required for multiple small CSF leaks.

This case presented the clinical challenge of managing a CSF leak at an unknown location. While EBP distant from the leak site can be effective, ${ }^{21}$ the preferred technique is to inject the blood at the level of the leak. ${ }^{12}$ Our approach was to start with a lumbar injection and, when that proved ineffective, to move progressively cephalad with the intent of maximizing the spread of blood throughout the epidural space. For the same reason, the latter two EBPs were done alternating first to the right then to the left decubitus position.

The optimal volume of blood to inject remains unknown. It has been shown that blood injected during an EBP typically travels nine spinal segments (six segments cephalad and three segments caudad) depending on the volume of blood injected. ${ }^{22}$ Many publications suggest an injectate volume up to $20 \mathrm{~mL},{ }^{12,23}$ yet there are reports of volumes greater than $20 \mathrm{~mL}{ }^{11,24}$ Most experienced clinicians have observed that there is a large and unpredictable variation in the volume of injected blood that elicits symptoms. The risk of a large volume injectate, which is essentially creating a temporary epidural hematoma, must be balanced with the risk of inadequate volume and possibly failing to patch the leak. After the first unsuccessful EBP using $20 \mathrm{~mL}$, we chose to inject volume to the endpoint of symptoms of back pain and/or radicular pain. This strategy resulted in the two latter EBPs being what would be considered higher-volume patches. Without controlled studies to guide clinical practice, we postulate that this approach is a reasonable one that will optimize the spread of the blood in the epidural space.

Rebound intracranial hypertension has been reported after EBP for SIH, which resolved without treatment. ${ }^{25}$ Other potential complications include arachnoiditis, presumably from blood crossing into the CSF, lumbovertebral syndrome, acute meningeal irritation, deterioration of mental status, and transient bradycardia. ${ }^{11}$ Post-procedure contact with the patient, in person or by telephone, would be prudent clinical practice to monitor the effects of the EBP as well as any potential complications.

The number of blood patches that should be performed is unknown, although three patches have been reported in the obstetric population. ${ }^{11}$ Alternate diagnoses should be considered when there is no response. In this case, the history and imaging were diagnostic of SIH. A third EBP was performed solely because of the partial response to the second EBP, and at the patient's request. Although not performed here, spinal MRI after a blood patch could provide information about the spread of blood in the epidural space and provide guidance for future therapy in challenging cases.
In conclusion, we report a series of EBPs to treat SIH from a leak at an unknown site in a patient suffering from intractable SIH-induced headache. This experience suggests that consideration be given to titrating injectate volume to back discomfort or radicular pain rather than using a pre-determined amount of autologous blood, and to performing repeated patches progressing up the spine when the level of the leak is unknown.

Disclosure There are no conflicts of interest by either of the authors relating to the content of this manuscript. There were no funding sources and no commercial affiliations relating to the content of this manuscript.

\section{References}

1. Schaltenbrand G. Neuere Anschauungen zur Pathophysiologie der Liquorzirkulation. Zentralbl Neurochir 1938; 3: 290-300.

2. Benzon HT, Nemickas R, Molloy RE, Ahmad S, Melen O, Cohen B. Lumbar and thoracic epidural blood injections to treat spontaneous intracranial hypotension. Anesthesiology 1996; 85: 920-2.

3. Diaz JH. Epidemiology and outcome of postural headache management in spontaneous intracranial hypotension. Reg Anesth Pain Med 2001; 26: 582-7.

4. Moayeri NN, Henson JW, Schaefer PW, Zervas NT. Spinal dural enhancement on magnetic resonance imaging associated with spontaneous intracranial hypotension. Report of three cases and review of the literature. J Neurosurg 1998; 88: 912-8.

5. Rozec B, Guillon B, Desal H, Blanloeil Y. Early blood-patch for spontaneous intracranial hypotension. Can J Anesth 2004; 51: 944-5.

6. Weitz SR, Drasner K. Spontaneous intracranial hypotension: a series. Anesthesiology 1996; 85: 923-5.

7. Hannerz J, Dahlgren G, Irestedt L, Meyerson B, Ericson K. Treatment of idiopathic intracranial hypotension: cervicothoracic and lumbar blood patch and peroral steroid treatment. Headache 2006; 46: 508-11.

8. Kantor D, Silberstein SD. Cervical epidural blood patch for low CSF pressure headaches. Neurology 2005; 65: 1138.

9. Rai A, Rosen C, Carpenter J, Miele V. Epidural blood patch at C2: diagnosis and treatment of spontaneous intracranial hypotension. AJNR Am J Neuroradiol 2005; 26: 2663-6.

10. Peng PW, Farb R. Spontaneous C1-2 CSF leak treated with high cervical epidural blood patch. Can J Neurol Sci 2008; 35: 102-5.

11. Banks S, Paech M, Gurrin L. An audit of epidural blood patch after accidental dural puncture with a Tuohy needle in obstetric patients. Int J Obstet Anesth 2001; 10: 172-6.

12. Grimaldi D, Mea E, Chiapparini L, et al. Spontaneous low cerebrospinal pressure: a mini review. Neurol Sci 2004; 25(Suppl 3): S135-7.

13. Schievink WI. Spontaneous spinal cerebrospinal fluid leaks and intracranial hypotension. JAMA 2006; 295: 2286-96.

14. Mokri B, Maher CO, Sencakova D. Spontaneous CSF leaks: underlying disorder of connective tissue. Neurology 2002; 58 : 814-6.

15. Schievink WI, Meyer FB, Atkinson JL, Mokri B. Spontaneous spinal cerebrospinal fluid leaks and intracranial hypotension. J Neurosurg 1996; 84: 598-605.

16. Inamasu J, Guiot BH. Intracranial hypotension with spinal pathology. Spine J 2006; 6: 591-9.

17. Duffy PJ, Crosby ET. The epidural blood patch. Resolving the controversies. Can J Anesth 1999; 46: 878-86. 
18. Ferrante E, Savino A, Sances G, Nappi G. Spontaneous intracranial hypotension syndrome: report of twelve cases. Headache 2004; 44: 615-22.

19. Berroir S, Loisel B, Ducros A, et al. Early epidural blood patch in spontaneous intracranial hypotension. Neurology 2004; 63: 1950-1.

20. Paldino M, Mogilner AY, Tenner MS. Intracranial hypotension syndrome: a comprehensive review. Neurosurg Focus 2003; 15: $\mathrm{ECP} 2$.

21. Ferrante E, Arpino I, Citterio A. Is it a rational choice to treat with lumbar epidural blood patch headache caused by spontaneous cervical CSF leak? Cephalalgia 2006; 26: 1245-6.
22. Szeinfeld M, Ihmeidan IH, Moser MM, Machado R, Klose KJ, Serafini AN. Epidural blood patch: evaluation of the volume and spread of blood injected into the epidural space. Anesthesiology 1986; 64: 820-2.

23. Gaiser R. Postdural puncture headache. Curr Opin Anaesthesiol 2006; 19: 249-53.

24. Chen HH, Huang CI, Hseu SS, Lirng JF. Bilateral subdural hematomas caused by spontaneous intracranial hypotension. J Chin Med Assoc 2008; 71: 147-51.

25. Tsui $H$, Wu $S$, Kuо $H$, Chen $C$. Rebound intracranial hypertension after treatment of spontaneous intracranial hypotension. Eur J Neurol 2006; 13: 780-2. 